APPARATUS FOR TESTING

SMOOTH AND RIBBED TUBING

WITH PULSED EDDY CURRENTS

by

A. Sather

BASE TECHNOLOGY

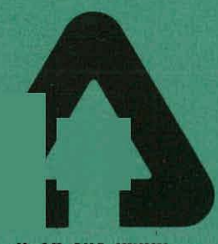

UotC-Aua-usuve

ARGONNE NATIONAL LABORATORY, ARGONNE, ILLINOIS

Prepared for the U. S. DEPARTMENT OF ENERGY under Contract W-31-109-Eng-38 


\section{DISCLAIMER}

This report was prepared as an account of work sponsored by an agency of the United States Government. Neither the United States Government nor any agency Thereof, nor any of their employees, makes any warranty, express or implied, or assumes any legal liability or responsibility for the accuracy, completeness, or usefulness of any information, apparatus, product, or process disclosed, or represents that its use would not infringe privately owned rights. Reference herein to any specific commercial product, process, or service by trade name, trademark, manufacturer, or otherwise does not necessarily constitute or imply its endorsement, recommendation, or favoring by the United States Government or any agency thereof. The views and opinions of authors expressed herein do not necessarily state or reflect those of the United States Government or any agency thereof. 


\section{DISCLAIMER}

Portions of this document may be illegible in electronic image products. Images are produced from the best available original document. 
The facilities of Argonne National Laboratory are owned by the United States Government. Under the terms of a contract (W-31-109-Eng-38) between the U. S. Department of Energy, Argonne Universities Association and The University of Chicago, the University employs the staff and operates the Laboratory in accordance with policies and programs formulated, approved and reviewed by the Association.

\section{MEMBERS OF ARGONNE UNIVERSITIES ASSOCIATION}

The University of Arizona Carnegie-Mellon Univer sity Case Western Reserve University The University of Chicago University of Cincinnati Illinois Institute of Technology University of Illinois Indiana University Iowa State University

The University of Iowa
Kansas State University The University of Kansas Loyola University Marquette University Michigan State University The University of Michigan University of Minnesota Univer sity of Missouri Northwestern University Universily of Notre Dame
The Ohio State University

Ohio University

The Pennsylvania State University Purdue University

Saint Louis University

Southern Illinois Univer sity The University of Texas at Austin Washington University

Wayne State University

The University of Wisconsin

\section{NOTICE}

This report was prepared as an account of work sponsored by the United States Government. Neither the United States nor the United States Department of Energy, nor any of their employees, nor any of their contractors, subcontractors, or their employees, makes any warranty, express or implied, or assumes any legal liability or responsibility for the accuracy, completeness or usefulness of any information, apparatus, product or process disclosed, or represents that its use would not infringe privately-owned rights. Mention of commercial products, their manufacturers, or their suppliers in this publication does not imply or connote approval or disapproval of the product by Argonne National Laboratory or the U. S. Department of Energy.

Printed in the United States of America

Available from

National Technical Information Service

U. S. Department of Commerce 5285 Port Royal Road

Springfield, Virginia 22161

Price: Printed Copy $\$ 4.50$; Microfiche $\$ 3.00$ 
Distribution Category:

LMFBR Fuels and Materials Engineering and Development (UC-79b)

ANL-77-53

\section{ARGONNE NATIONAL LABORATORY \\ 9700 South Cass Avenue \\ Argonne, Illinois 60439}

\section{APPARATUS FOR TESTING SMOOTH AND RIBBED TUBING WITH PULSED EDDY CURRENTS}

by

A. Sather

Materials Science Division

May 1978

This report was prepared as an account of work

sponsored by the United STes Covement. Neither the

United States nor the Unites states Depal useul of

Energy, nor any of their employees, nor any of their

contractors, subcontractors, or their employees, makes

any warranty, express or implied, or assumes any legal

liability or responsibility for the accuracy, completeness

or usefulness of any information, apparatus, product or

process diselosed, or represents that its use would not

infringe privately owned rights. 
THIS PAGE

WAS INTENTIONALLY

LEFT BLANK 
TABLE OF CONTENTS

$\underline{\text { Page }}$

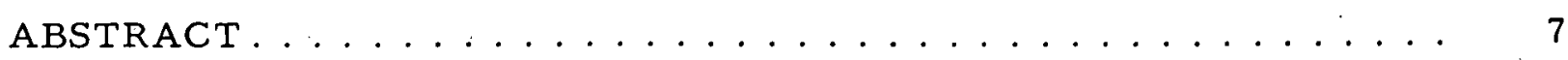

I. INTRODUCTION $\ldots \ldots \ldots \ldots \ldots \ldots \ldots \ldots \ldots \ldots \ldots \ldots \ldots \ldots$

II. THEORY OF OPERATION . . . . . . . . . . . . 7

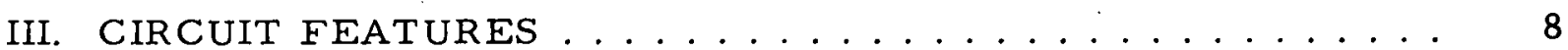

IV. ADJUSTMENT OF SAMPLE POINTS ............. 9

V. DESCRIPTION AND USE OF TRANSDUCERS. . . . . . . . 12

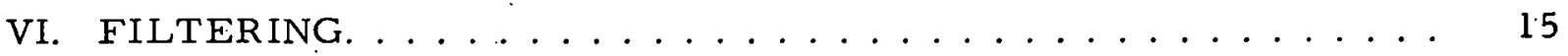

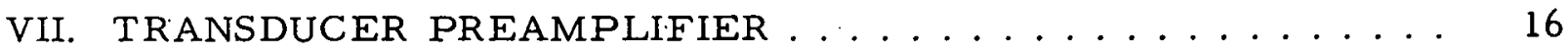

VIII. PULSE-FORMING NETWORK FOR WALL-THICKNESS PROBE . 16

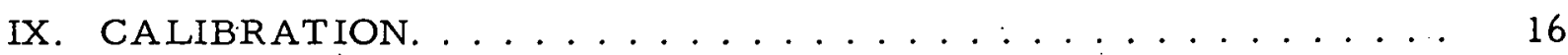

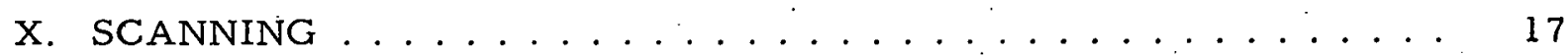

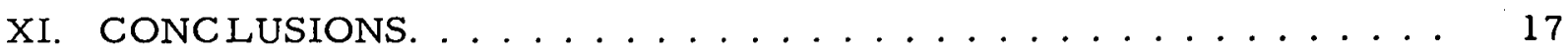

APPENDIX: Circuit-board Electrical Diagrams .......... 18

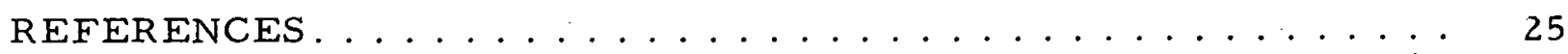




\section{LIST OF FIGURES}

No.

Title

$\underline{\text { Page }}$

1. Pulsed Eddy-current System in Its Simplest Form. . . . . . . .

2. Voltage Developed across the Defect-transducer Pickup as a Function of Time with Lift Off as a Parameter........... 10

3. Voltage across the Defect-transducer Pickup as a Function of Time for a Normal and an Inner-surface-defect Tube. . . . . . . .

4. Voltage across the Defect-transducer Pickup as a Function of Time for a Normal and an Outer-surface-defect Tube .......

5. Voltage across the Defect-transducer Pickup as a Function of Time for Normal Tubes, One Empty and One with an Internal Cylinder of Stainless Steel. . . . . . . . . . . . . . . .

6. Vullage across the Wall-thickness Transduccr Pickup as a Function of Time for Tubes of Two Wall Thicknesses. . . . . . .

7. View of the Specimen End of the Defect-detection Transducer fur Smooth Tubing . . . . . . . . . . . . . . . . . .

8. View of the Specimen End of the Defect-detection Transducer

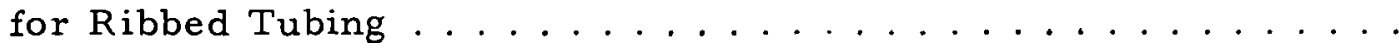

9. View of the Specimen End of the Wall-thickness Measurement Transducer. ........................

10. Defect Sensitivity Pattern of Typical Pulsed Eddy-current Transducer Optimally Located with Respect to a $6.35 \mathrm{~mm}$ Outside Diameter Tuhe with a $0.33-\mathrm{mm}$ Wall Thickness . . . . . .

i 1. Filtered and Unfiltered Results from Pulsed Eddy-current Test of Tubing with EDM Inside Diameter Notches. . . . . . . .

12. Filtered and Unfiltered Pulsed Eddy-current Test Results from a Sample 'I'ube with EDM Outside Diameter NotcheE......

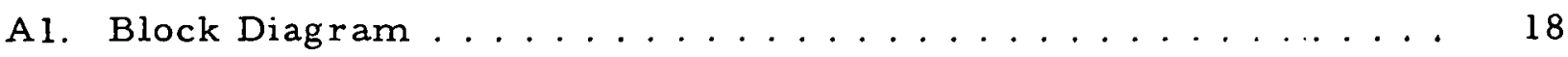

A2. System Clock ........................ 18

A3. Field-coil Pulser, . . . . . . . . . . . . . . . . . . . 19

A4. Pickup Preamplifier for Defect Section . . . . . . . . . . . 19

A5. Wall-thickness Section Pulse-forming Network. . . . . . . . 19

A6. Wall-thickness Section Sampling Gate . . . . . . . . . . . . 20

A7. Defect Section Sampling Gate................. 21

A8. Wall-thickness Section Broadband Filter with Add-Subtract Circuit. ........................ 


\section{LIST OF FIGURES}

No.

Title

Page

A9. Wall-thickness Section Broadband Filter Inverter Buffers . . . . 22

A10. Defect Section Broadband Filter with Add-Subtract Circuit . . . 23

Al1. Defect Section Broadband Filter ............... 23

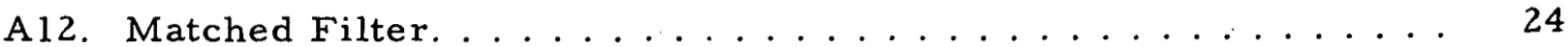

A13. Power Supply. ....................... 24 


\section{THIS PAGE}

\section{WAS INTENTIONALLY LEFT BLANK}




\title{
APPARATUS FOR TESTING SMOOTH AND RIBBED TUBING WITH PULSED EDDY CURRENTS
}

by

A. Sather

\begin{abstract}
The use of outside diameter ribs on nuclear reactor tubing presents severe problems to nondestructive testing of this tubing. A pulsed eddy-current apparatus for inspecting the integrity of smooth and ribbed tubing has been developed at Argonne National Laboratory. Test. results for this apparatus and analysis and circuit block diagrams are presented. In addition, transducer and preamplifier features, scanning procedures, and theory of operation are discussed. To date, this apparatus has provided the best solution to the ribbed tubing problem because of its capability to time-sample data.
\end{abstract}

\section{INTRODUCTION}

Severe problems occur in nondestructive testing of nuclear reactor tubing with outside diameter ribs. A pulsed eddy-current apparatus for inspecting the integrity of smooth and ribbed tubing has been developed at Argonne National Laboratory (ANL). The spacing between the probe and the sample has always presented problems when eddy currents are used in nondestructive testing. This lift-off problem, which could become quite severe when testing ribbed tubing, can be minimized using pulsed eddy currents. Sampling of the pulses at voltage waveform crossing points for various parameters enables the present pulsed eddy-current system to minimize the lift-off effect, which then becomes only a minor interference. Combining this. advantage and the use of a differential pickup system enables ins pection of the wall integrity of a tube with $0.15-\mathrm{mm}$-high ribs without maintaining highly accurate mechanical spacing.

\section{THEORY OF OPERATION}

The essential features of operation of the pulsed eddy-current test system are as follows:

a. A pulse of current flows in a field coil, which produces an electromagnetic field in the space that surrounds the coil. The intensity of this electromagnetic field varies with time. 
b. A system of currents is induced in any conducting specimen within the field of the coil. The currents diffuse into the specimen and can be reflected by discontinuities such as geometrical boundaries, defects, and layers of material with different electrical conductivities.

c. These reflected currents are detected as pulses of voltage at the terminal of a pickup coil located near the specimen.

d. The voltage pulse is processed by various types of circuitry to extract pertinent information about the test specimen and present it in a useful form.

Two of the most important advantages of pulsed eddy-current testing are:

a. The pulsed driving current produces an inherently wideband signal. In principle, this permits extraction of more selective information than can be determined from the test specimen by an eddy-current method.

b. The low duty cycle of the pulse permits generation of relatively high peak electromagnetic fields around the specimen. Because of the high fields, transducers can be designed with ruggedness and resolution that cannot be attained in transducers used with conventional sinusoidal eddy-current equipment.

\section{CIRCUIT FEATURES}

A pulsed eddy-current test system in its simplest form is shown in Fig. 1. A pulse generator produces a train of current pulses thal flow into

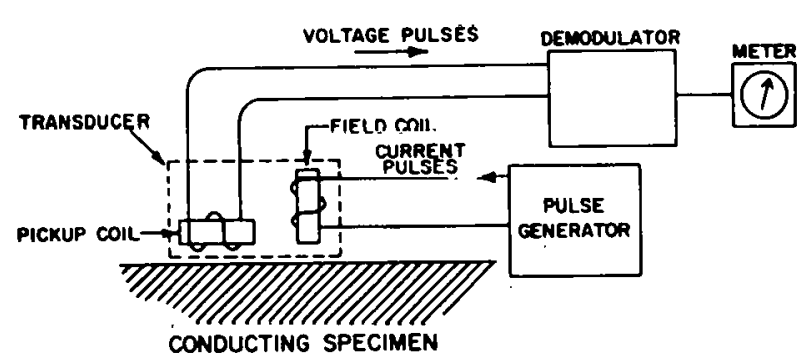

Fig. 1. Pulsed Eddy-current System in Its Simplest Form. Neg. No. MSD-57852. the field coil and induce currents in the specimen. The total pulsed field, which is the sum of all currents flowing in the coil and specimen, produces a train of voltage pulscs at the terminal of a pickup coil. This train of pulses must be smoothed and filtered by the demodulater before it ran he displayed on a meter.

Service pulsed eddy-current instruments contain considerably more function modules than the system in Fig. 1. The pickup voltage pulse must usually be amplified before it is subjected to other signal processing. As the test probe is brought close to a metallic specimen, the voltage pulse, which is observed on an oscilloscope, changes in a complicated manner. The extraction of all information from the pickup pulse requires that it be subjected to more 
processing than simple demodulation. In the present system, this extraction is performed by time sampling. A pickup voltage pulse can be sampled at various discrete time intervals (sample points), amplified, and smoothed, thus providing separate instrument outputs.

The test system consists of two nearly independent sections, each of which has four outputs, labeled WT1 through WT4 and Dl through D4, respectively (see circuit diagrams in the Appendix). In tube testing, it is intended that the section with outputs WTl through WT4 be used for wall-thickness measurements and the section with outputs Dl through D4 for the detection of defects, although the system is versatile and capable of many other applications. Each output of the two sections is associated with a particular sample point of the pickup voltage pulse. Each section has one transducer, and each transducer field coil is supplied current pulses by a separate pulser. The pulsers are fired alternately by master-clock circuitry (labeled system clock in the Appendix), and the repetition rate of the pulses sent through each field coil can . be adjusted up to $2 \mathrm{kHz}$. A separate synchronizing pulse is supplied by each pulser, which facilitates oscilloscope operations. Time sampling is accomplished in the circuits labeled sampling gates (Appendix). For each sample point, an external connection, test point 2 (T.P. 2 ), is provided that can be used for proper time adjustment and oscilloscope viewing of the pickup voltage pulse. The signal outputs of sampling gates WT1, WT2, D1, and D2 are fed to addsubtract circuits that can be used for reduction of lift-off signals.* In addition, the outputs of the defect-detection section (Dl through D4) pass through filter circuits that enhance the sensitivity of the system to small defects. The operation of these filters is discussed in Sec. VI. Each sampling gate is provided with a front-panel zeroing control that reduces the bias voltage of the particular output to zero. The bias voltage at any output can be monitored by a frontpanel meter. The operation of the system is not affected by moderate $( \pm 10 \mathrm{~V})$ offsets. If the test system is connected to an analog-to-digital converter for computer processing of the output signals, the zeroing controls are useful for maintaining the variation around a zero average value.

\section{ADJUSTMENT OF SAMPLE POINTS}

As mentioned above, information from the voltage pulse developed across the pickup coil is extracted by sampling the waveform at various times. However, it is advantageous to carefully choose the timing of the sample points. Figure 2 is a reproduction of oscilloscope waveforms obtained at T.P. 2 from one of the sample-gate circuits of the defect section. The three curves correspond to three values of lift-off distance. Two times (not including the origin) exist at which the same signal is produced for all

"Lift-off signals cause variations in the system output and result from changes in the spacing between the spacing between the test specimen and transducer. Unless these signals are suppressed, they may interfere with the propcr interpretation of the test results. 


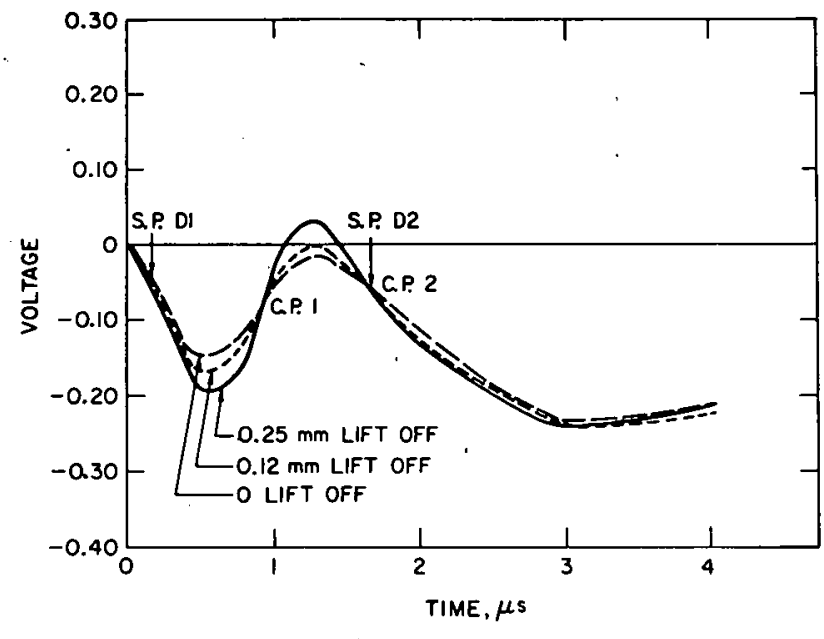

Fig. 2. Voltage Developed across the Defecttransducer Pickup as a function of Time with Lift Off as a Parameter. Neg. No. MSD-64466. three lift-off values. These points, known as crossing points, ${ }^{2}$ are marked C.P. 1 and C.P. 2. Crossing points also exist for other test parameters. One technique for choosing the sample point is to time sample at a crossing point, for a particular parameter, at which satisfactory sensitivity to a second parameter exists. The signal at this sample point will then be a function of the second variable but not of the first. For example, if lift off is a problem and one wishes to detect inner-surface notches, choosing sample point 2 of the defect section (S.P. D2) to be at C.P. 2 will result in low sensitivily to lift off but good sensitivity to inner-surface defects, as can be determined by a comparison of Figs. 2 and 3. For this example, time sampling at C.P. 1 is insensitive to both lift-off and inner-surface defects but is quite sensitive to outer-surface faults, as shown in Fig. 4. The crossingpoint phenomenon is a basic feature of pulsed eddy-current testing. With two test parameters, a crossing point will always exist. In another instance, the two waveforms in Fig. 5 were obtained from a tube with and without a stainless steel slug, which was slipped into the tube with only a few hundredths of a millimeter of clearance. This slug simulates, for example, a restrainer inside a fuel element. The crossing point, that is, the point of minimum sensitivity to internal conductors of this type, is obvious. Figure 5 also shows another significant feature of the voltage-pulse waveforms developed across the pickup coils: a finite time is required for the bulk of

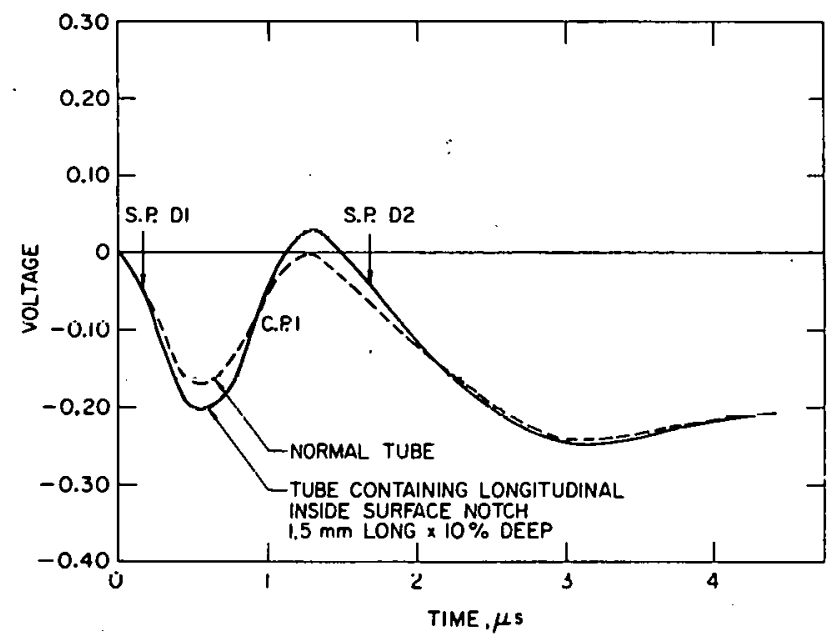

Fig. 3. Voltage across the Defect-transducer Pickup as a Function of Time for a Normal and an Inner-surface-defect Tubc. Neg. No. MSD-64463.

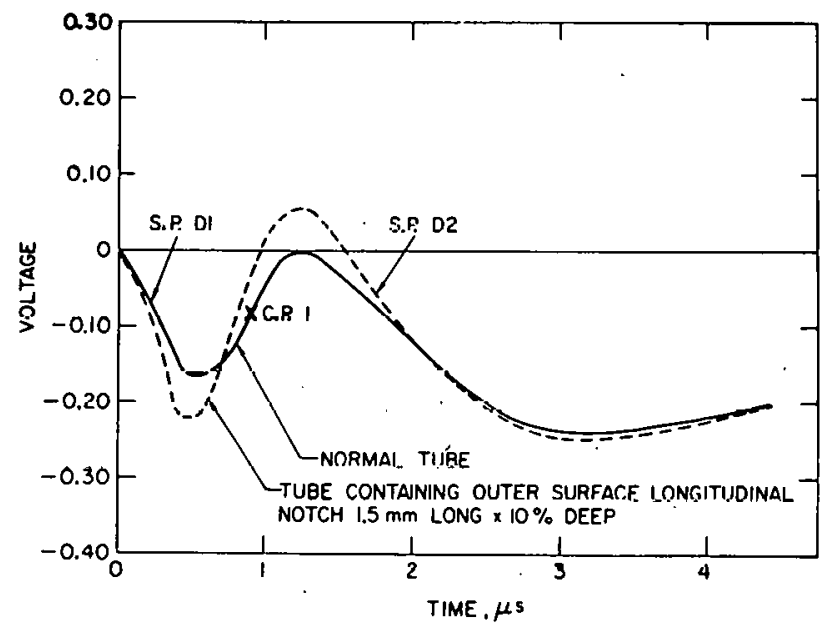

Fig. 4. Voltage across the Defect-transducer Pickup as a Function of Time for a Normal and an Outer-surface-defect Tube. Neg. No. MSD-64467. 


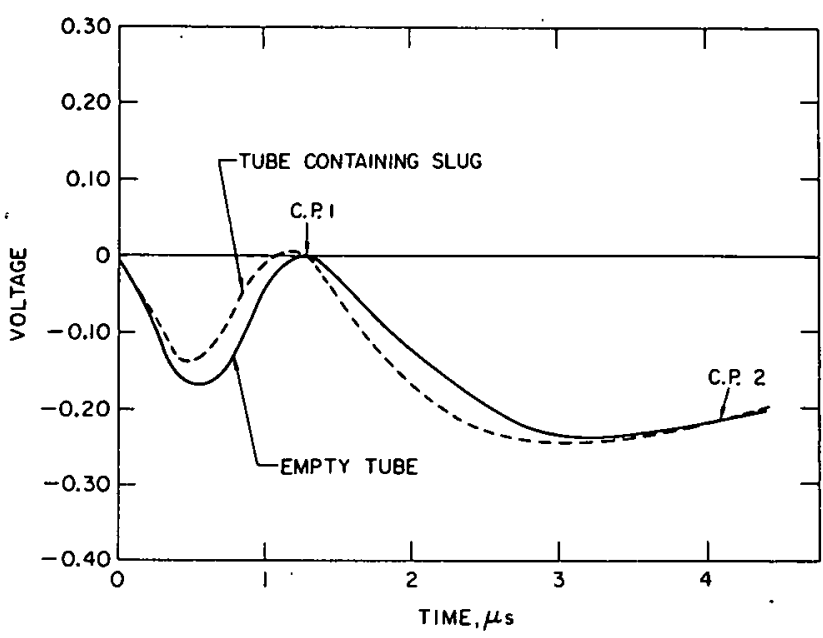

Fig. 5. Voltage across the Defect-transducer Pickup as a Function of Time for Normal Tubes, One Empty and One with an Internal Cylinder of Stainless Steel. Neg. No. MSD-64464. the current to flow into the specimen and be reflected and detected by the pickup. Virtually no difference exists, for the first $0.15 \mu \mathrm{s}$, between the waveforms from the empty tube and the tube that contains the slug. A comparison of Fig. 5 with Fig. 4 indicates the effect of a surface defect. In Fig. 4 the differences are practically instantaneous and subside much quicker. In addition, crossing points in the defect case (Fig. 4) occur much sooner when compared with those for the slug case (Fig. 5).

The crossing points are not locations of absolute invariance but only of minimum sensitivity to a

particular parameter. If sufficient suppression of undesirable data is not available using a crossing point or if a crossing point is not conveniently located, the signals from two sample points may have to be linearly combined to produce the necessary suppression of these data. For example, if it were necessary to perform a test to detect small inner-surface defects with a test rig that permitted considerable lift-off variation, undesirable lift-off data could be minimized using S.P. D2 (Figs. 2 and 3), which is a crossing point for lift off (Fig. 2). Although time sampling at S.P. Dl is almost completely insensitive to inner-surface defects (Fig. 3), it possesses some sensitivity to lift off (Fig. 2). Thus, signals from S.P. D1 and D2 could be combined in an add-subtract circuit (Appendix) with the proper polarity and amplitude to eliminate the remainder of the lift-off signal. One of these add-subtract circuits, with front-panel gain adjustments and polarity switches, is provided for each section of the test system.

Slight variations can be expected in the waveforms produced by defect transducers because of differences in as sembly. However, these variations are insignificant; all defect transducers fabricated for use in the present system are standardized for sensitivity, and the crossing points for each are essentially identical. When the sample points for the wall-thickness section are chosen, the same principles as outlined for the defect section are followed. As a result of the construction of the wall-thickness transducer, its waveform is somewhat different. The variation in the waveform produced at T.P. 2 for the wall-thickness section is shown in Fig. 6 for tubes of two slightly different wall thicknesses. 


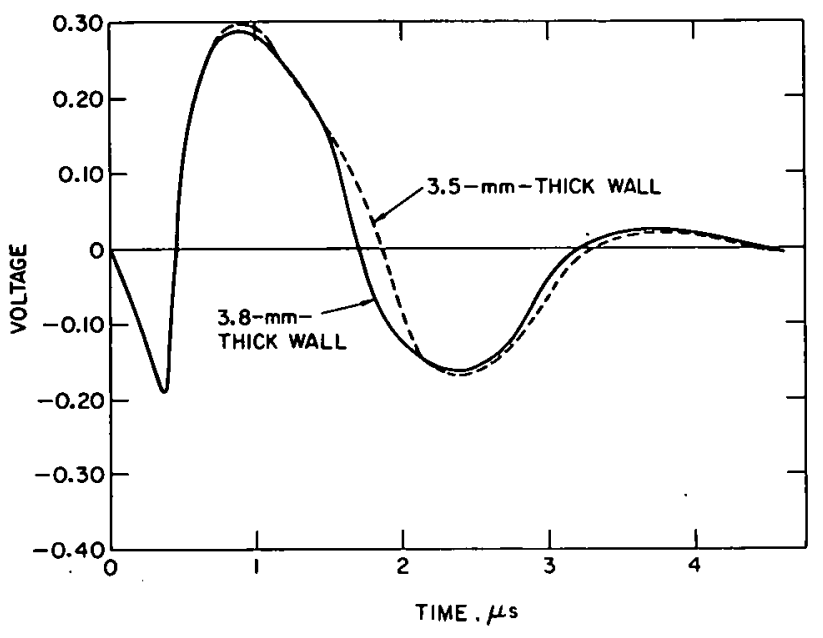

Fig. 6

Voltage across the Wall-thickness Transducer Pickup as a Function of Time for Tubes of Two Wall Thicknesses. Neg. No. MSD-64465.

\section{DESCRIPTION AND USE OF TRANSDUCERS}

The test system has two types of transducers, one for defect detection and the other for wall-thickness measurement. Each transducer has one field coil. The wall-thickness transducer has one pickup coil and the defectdetection transducer has two, which act as a differential pickup coil. The defect transducer is designed for high resolution, which results in a short point-defect response. ${ }^{3}$ A copper mask is used to produce a pulsed magnetic field with a sharp gradient, which is best for the detection of small defects. This transducer is specifically designed to detect tubing defects that are predominantly longitudinal (i.e., those with the major dimension parallel to the tube longitudinal axis); small transverse defects also can be detected with this probe. Large transverse defects (i.e., defects that cover more than $15^{\circ}$ of the circumference of the tube) are detected with reduced sensitivity when compared with the same defect oriented in the longitudinal direction. The proper orientation of a smooth tube or fuel element under the defect transducer is shown in Fig. 7. This is best determined by observing an oscilloscope. When the transducer is placed such that its center axis is coaxial with the tube radius and rotated, the amplitude of the oscilloscope trace changes. For the inspection of ribbed tubes, the proper transducer orientation is shown in Fig. 8. The ribs of the tube must be parallel to the center line of the two pickup coils such that no difference in balance of the coils is noted. This orientation angle, of course, will be equal to the angle of the rib. Alignment must be performed carefully to ensure a differential action from the pickup coils when a rib approaches. If the transducer is properly aligned, the ribs produce a small background signal, which can be compensated by signal processing. Proper alignment results in a minimum peak-to-peak voltage on the oscilloscope face for an unflawed specimen. The location of the wallthickness transducer is not as critical; it is placed in the position shown in Fig. 9, which can be accomplished by visual alignment. 


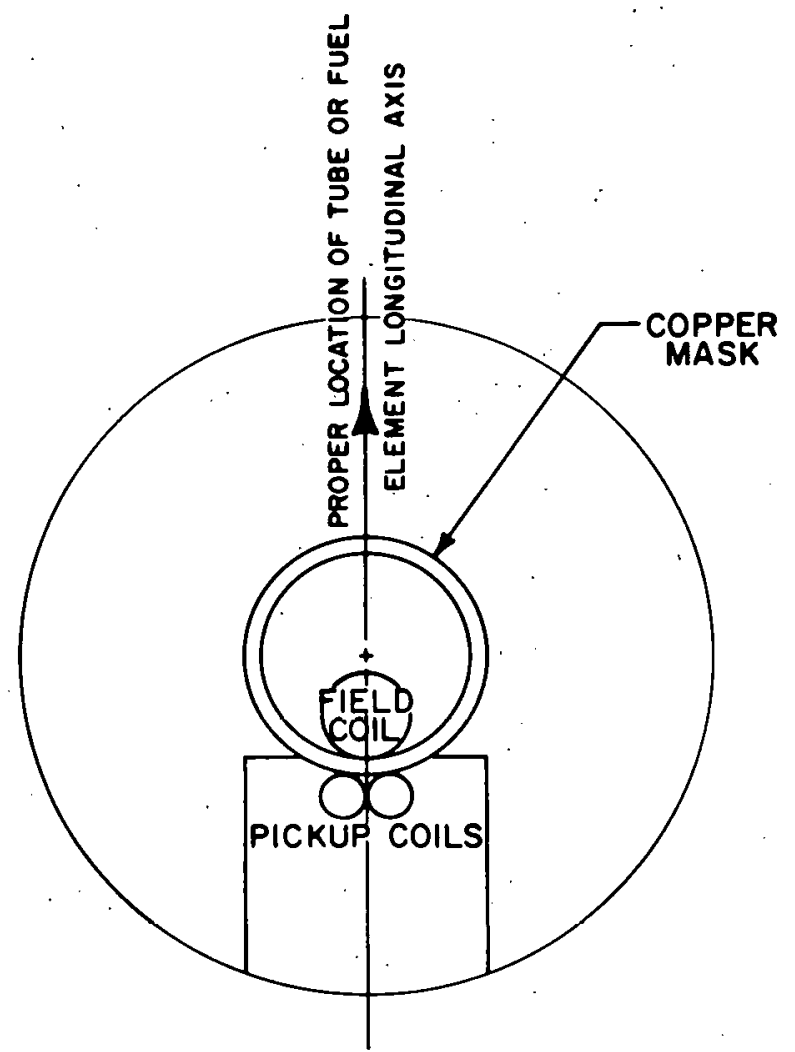

Fig. 7. View of the Specimen End of the Defectdetection Transducer for Smooth Tubing. Neg. No. MSD-57858.

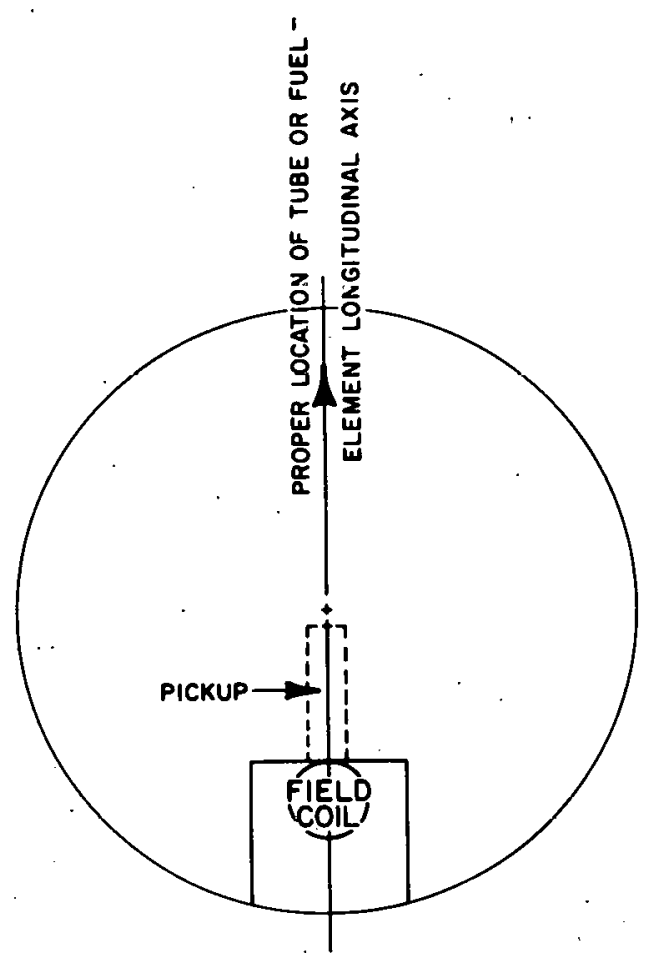

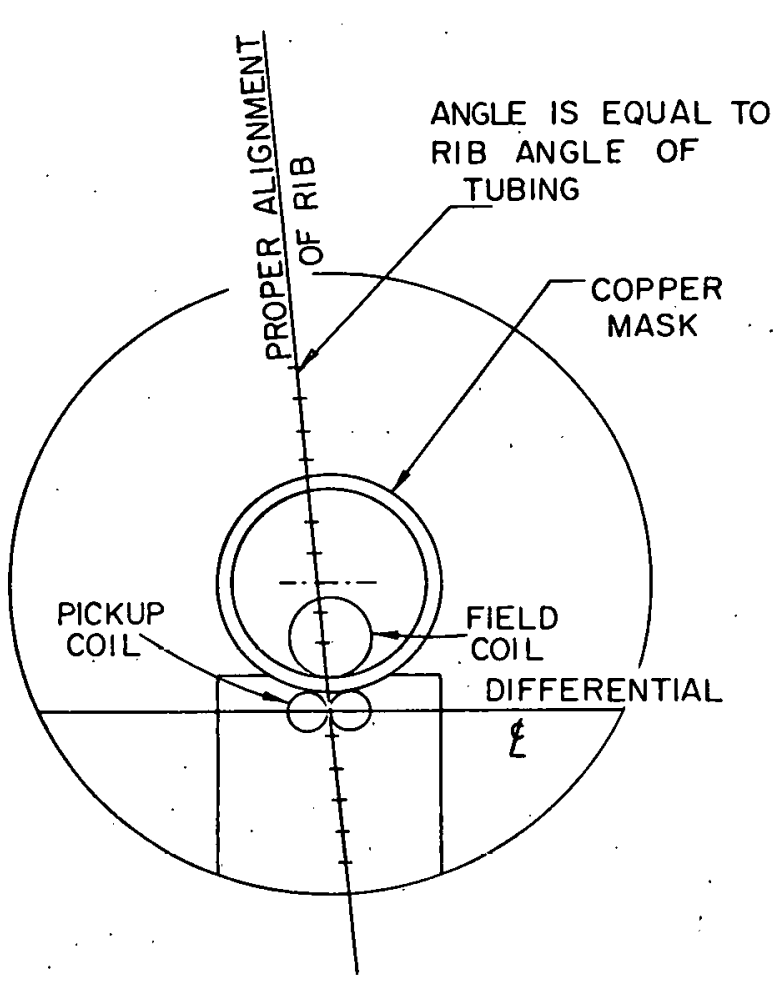

Fig. 8. View of the Specimen End of the Defectdetection Transducer for Ribbed Tubing. Neg. No. MSD-64079.

Fig. 9

View of the Specimen End of the Wallthickness Measurement Transducer. Neg. No. MSD-57859. 
The electromagnetic fields produced by the field coils of both transducers weaken rapidly as the probe-to-specimen distance increases. This lift off can affect system sensitivity. Consequently, the specimen tested must be within $0.5 \mathrm{~mm}$ of the transducer (preferably closer) for best sensitivity. An average spacing of lift off of $0.25 \mathrm{~mm}$ is a recommended value for most tests; thus, tubes with ribs $0.15 \mathrm{~mm}$ in height can be inspected. Although the procedures for setting the time-sampling pulses largely eliminate the lift-off signals at the output of the test system, they do not compensate for wallthickness calibration nor decreases in defect sensitivity. The amount of lift-off variation allowable depends upon the accuracy required by the test. Tube wobble (i.e., wandering of the tube longitudinal axis on either side of the transducer center axis) can also be a problem, expecially with the defect transducer, and should be maintained within $0.2 \mathrm{~mm}$. Wobble is more likely to produce a "noisy!" signal at the system output than to affect calibration appreciably.

Drift problems may be encountered in wall-thickness measurements, especially when obtained on fuel elements sufficiently active to produce significant heating. Drift originates from two sources: (a) heatup of sampling circuits and amplifiers, and (b) temperature-induced changes in the transducer, which involve resistivity of the wire, permeability of the ferrite core, and expansion of the materials. The first source usually becomes negligible after $30 \mathrm{~min}$ of warm-up, unless severe line-voltage changes are encountered. In this case, use of a line-voltage regulator is advisable.

Because the defect-detection transducer is designed to have much higher resolution than the wall-thickness transducer, it covers a smaller angle of the circumference of the tube. A typical sensitivity-response curve for a defect-detection transducer is shown in Fig. 10. The response is strongly dependent on the orientation of the transducer center axis with respect to the defect.

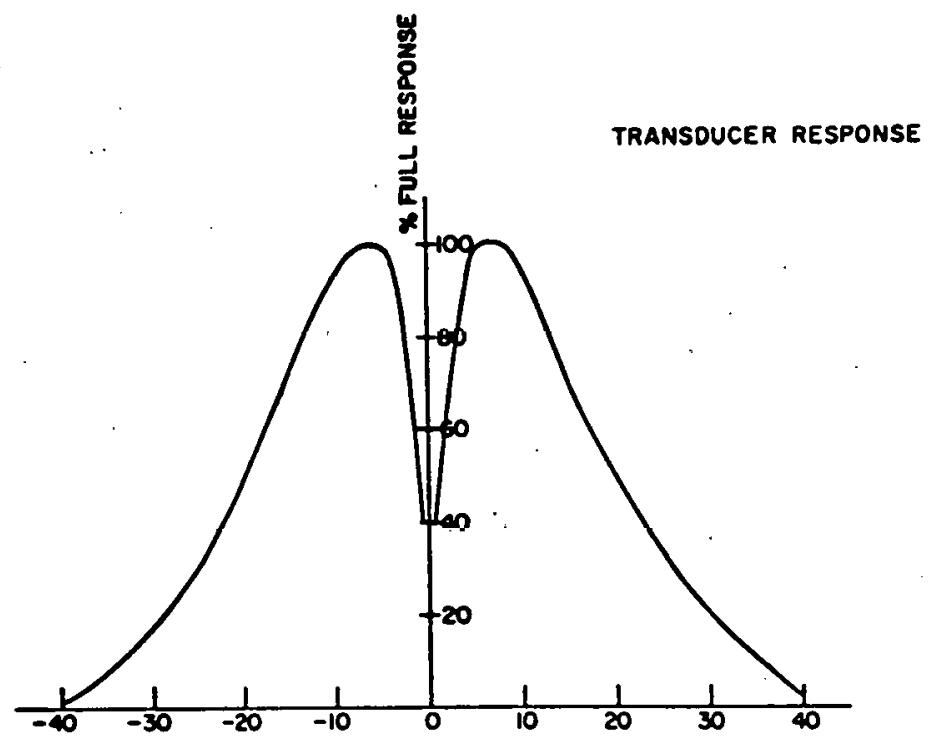

Fig. 10

Defecl Sensilivily Paltern of Typical Pulsed Eddy-current Transducer Op-; timally Located with Respect to a 6.35-mm Outside Diameter lube with a $0.33-\mathrm{mm}$ Wall Thickness. Neg. No. MSD-64077. 


\section{FILTERING}

The effective current field size selected for use in pulsed eddy-current tests is dependent upon the size of the defects to be detected. To facilitate this selection, filters have been designed for the defect-detection section of the test system. The filter-design philosophy has been described elsewhere. ${ }^{3-5}$ Two types of filters are used in the present test system: broadband and matched. The broadband filter is designed to provide maximum enhancement of the signals from small defects without unacceptable distortion and reduction of the signals from defects that have appreciable length along the fuel-element cladding. The matched filter is designed to provide the maximum signal-tonoise ratio from small defects without regard to distortion. The action of the two filters is shown in Fig. 11. The dangers inherent in the use of only the matched filter are illustrated in Fig. 12, which shows the test-system output that results from scanning a tube with several outer-surface, longitudinal, electric-discharge-machine (EDM) notches. The shape of these notches is shown in a cross-sectional view of the tube wall at the bottom of Fig. 12. Of particular interest is the response of the matched filter to the third notch from the left. This long, deep defect, which approximates the depth versus length profile of many cracks, is almost completely attenuated. On the other. hand, the capability of the matched filter to improve the signal-to-noise ratio for small defects is obvious.
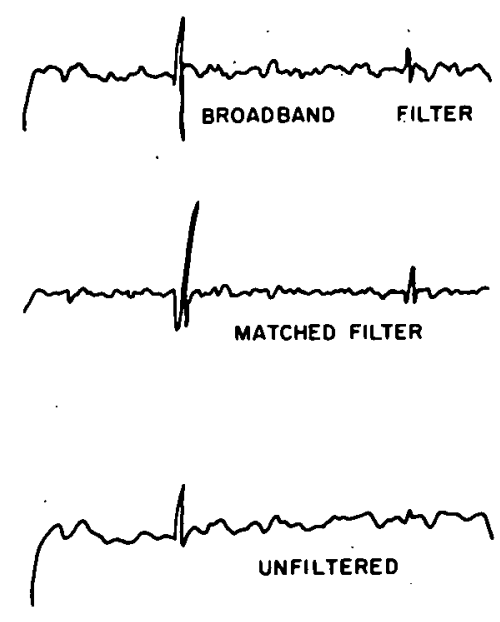

Fig. 11

Filtered and Unfiltered Results from Pulsed Eddy-current Test of Tubing with EDM Inside Diameter Notches. Sample is 5.6-mm-dia Type 316 stainless steel tube with a wall thickness of $0.04 \mathrm{~mm}$. Inner-surface notches are 20 and $10 \%$ deep and $1.6 \mathrm{~mm}$ long. $\mathrm{Neg}$. No. MSD-55296.
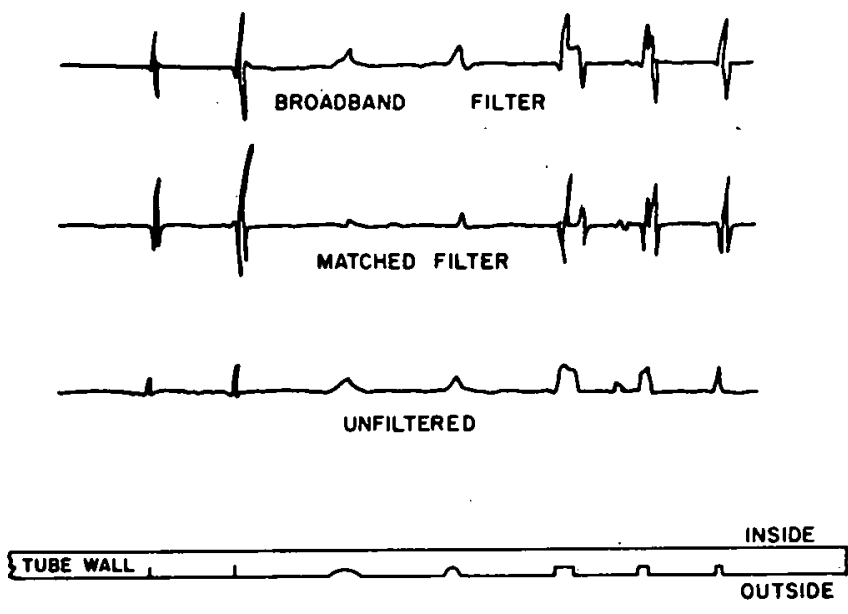

Fig. 12

Filtered and Unfiltered Pulsed Eddy-current Test Results from a Sample Tube with EDM Outside Diameter Notches. Neg. No. MSD-55295. 


\section{TRANSDUCER PREAMPLIFIER}

The defect-detection transducer requires a preamplifier (Appendix) that is located no more than $2 \mathrm{~m}$ away. Up to $15 \mathrm{~m}$ of coaxial cable can be used between the preamplifier and the remainder of the test system. The preamplifier is intended for operation within a hot cell. Actually, the preamplifier circuit consists of three preamplifiers, although the defect-detection section requires only one. The other two are provided as spares and for flexibility in the event that additional transducers are used. Thus, sufficient transducer preamplifiers and sampling circuits are available such that the system can easily be converted to a three-transducer defect-detection system with two sample points per transducer and a wall-thickness system with one transducer and two sample points. Note that the preamplifiers have a switch for output polarity.

\section{PULSE-FORMING NETWORK FOR WALL-THICKNESS PROBE}

The small box that contains the pulse-forming network is located near the wall-thickness probe (Appendix). A 15-m length of cable can be used between this box and the main chassis. The 50- $\Omega$ termination resistor is in the main chas sis.

\section{CALIBRATION}

Various depths of EDM notches are usually used for calibration of the defect-detection section. With a transducer lift off of $0.2 \mathrm{~mm}$, the test system easily detects both inner- and outer-surfáce longltudinal notches thial have a depth of $10 \%$ of the wall thickness and a length of $1.5 \mathrm{~mm}$. Sensitivity. is increased with smaller values of lift off. A 1.5-mm transverse notch produces a signal with an amplitude approximately two-thirds that for the same notch located longitudinally. Shorter transverse notches produce essentially the same signal as an identical notch located longitudinally. The sensitivity required for the detection of small notches may not be necessary in hul-cell work, particularly on high-burnup fuel elements. A variety of problems that do not occur in new tubing $c$ an be encountered in jackets of these fuel elements. Calibration of the system on a single isolated notch is not valid when many defects exist simultaneously in the field of the transducer. In this case, a buildup of the output signal usually results, which can lead to overestimation of the maximum defect depth.

Wall-thickness standards are most conveniently prepared by chemical etching to remove various thicknesses from the inner surface of a short section of tubing with the same size and composition as the tubing to be measured. Several short, etched sections of different wall thicknesses can be assembled in an array for a calibration standard. However, this type of standard, which has a relatively smooth inner surface, is not expected to facilitate reliable prediction of wall thinning in an irradiated fuel element. If wall thinning in the fuel element has been produced by a process that creates an irregular 
cladding inner surface or metallic fission products have accumulated within the field of the probe, the pulsed eddy-current equipment can only be relied upon to indicate the existence and location of an abnormality. Work on the development of standards and methods of interpretation of pulsed eddy-current tests on irradiated fuel elements has only recently begun at ANL and other locations.

\section{SCANNING}

The present pulsed eddy-current system has been designed for tests in which the fuel element is longitudinally scanned and circumferentially indexed until the entire surface of the tube has been inspected. This type of scanning usually produces the best signal-to-noise ratio at the output of the defect section. Slow spiraling of the fuel element relative to the transducer, with a pitch of $\sim 50 \mathrm{~mm}$, produces essentially the same result as longitudinal scanning. Scanning with a long-pitch spiral has been successfully used to test, at least partially, fuel elements and capsules with the spacing wires still attached. Rapid spiraling with a small pitch, which is necessary for ultrasonic tube testing, is not recommended. The filters used in the defect section have been designed for a scanning velocity of $2 \mathrm{~m} / \mathrm{min}$ for the transducer relative to the tube surface. Use at any other speed results in degradation of filter performance, although variations of $10 \%$ have little effect. Of course, the wall-thickness measurement section, which has no filters, can be used at any practical scanning speed.

Many methods of scanning are available that ensure coverage of the entire fuel-element surface by the defect-detection transducer. Once the conditions of the test (such as the required sensitivity and the mechanical scanning and positioning arrangements) have been determined, the tubeindexing increments can be selected by referring to Fig. 10.

\section{CONCLUSIONS}

Pulsed eddy-current testing with time sampling is a viable method for the inspection of smooth and ribbed tubing. The capability of the method to test integrity as well as measure wall thickness with great accuracy, overcoming lift-off interference, makes it one of the most valued nondestructive testing tools for tubing available at the present time.

The separation of defect data obtained from the inner and outer tube surfaces and measurement of wall thickness at any point along the tube, coupled with the speed and accuracy of an electronic test, provide all the information required for a good nondestructive evaluation.

Pulsed eddy-current equipment is not difficult to operate and will surely aid in solving many other nondestructive testing problems. 
APPENDIX

\section{Circuit-board Electrical Diagrams}

Circuit diagrams for the pulsed eddy-current test system are presented in Figs. Al-A13.

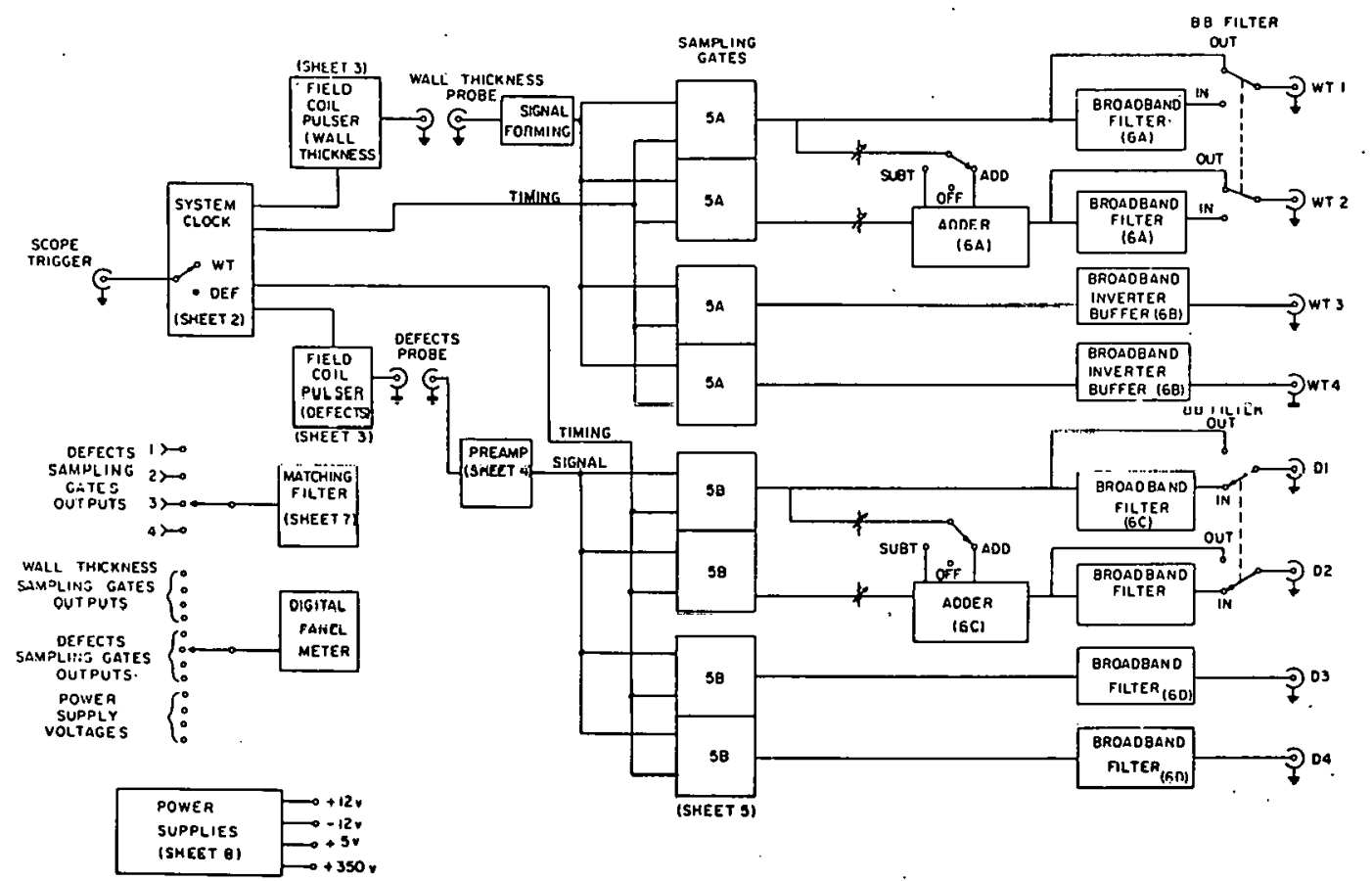

Fig. A1. Block Diagram. Neg. No. MŠL-64078.

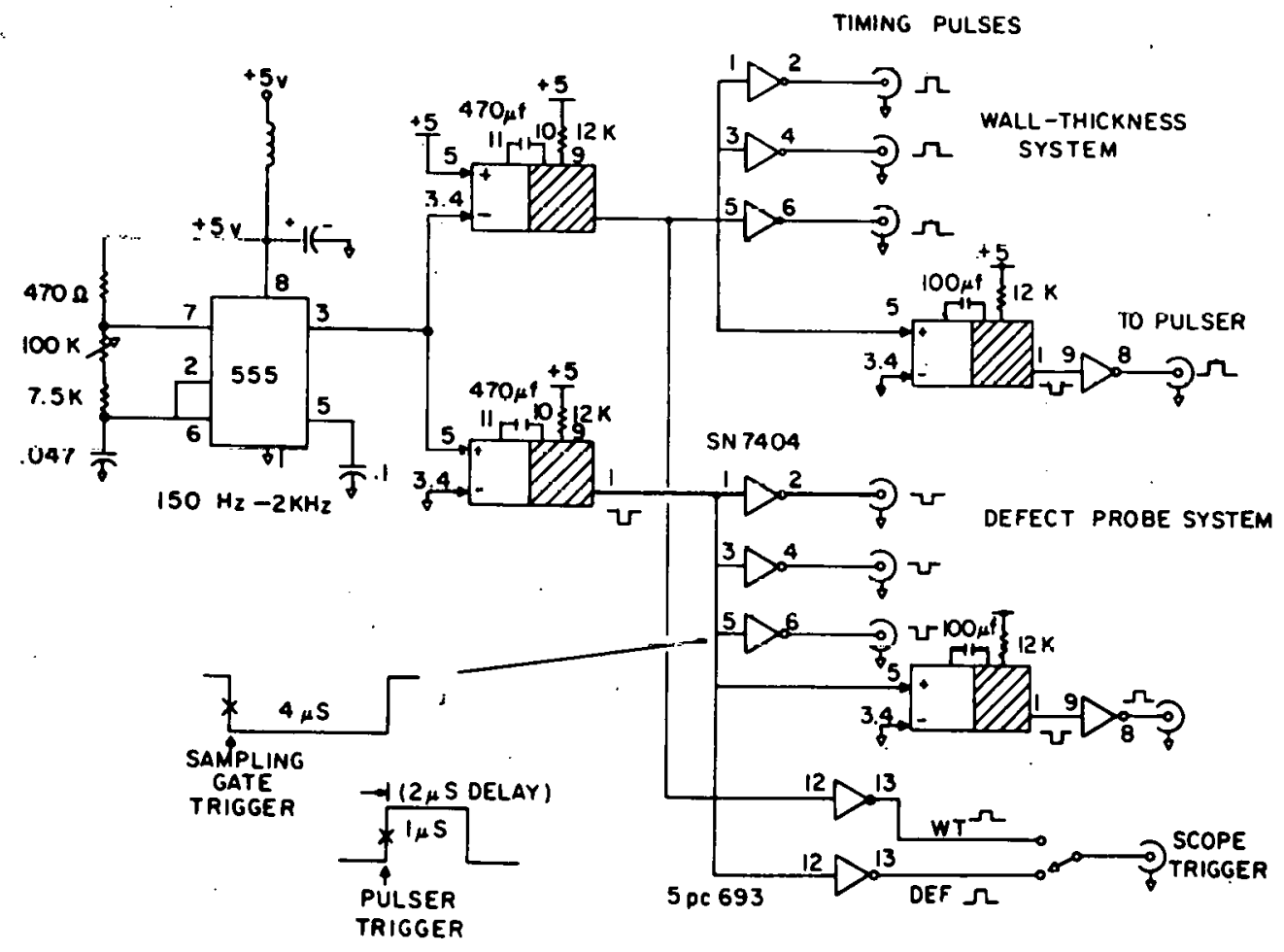

Fig. A2. System Clock. Neg. No. MSD-64161. 


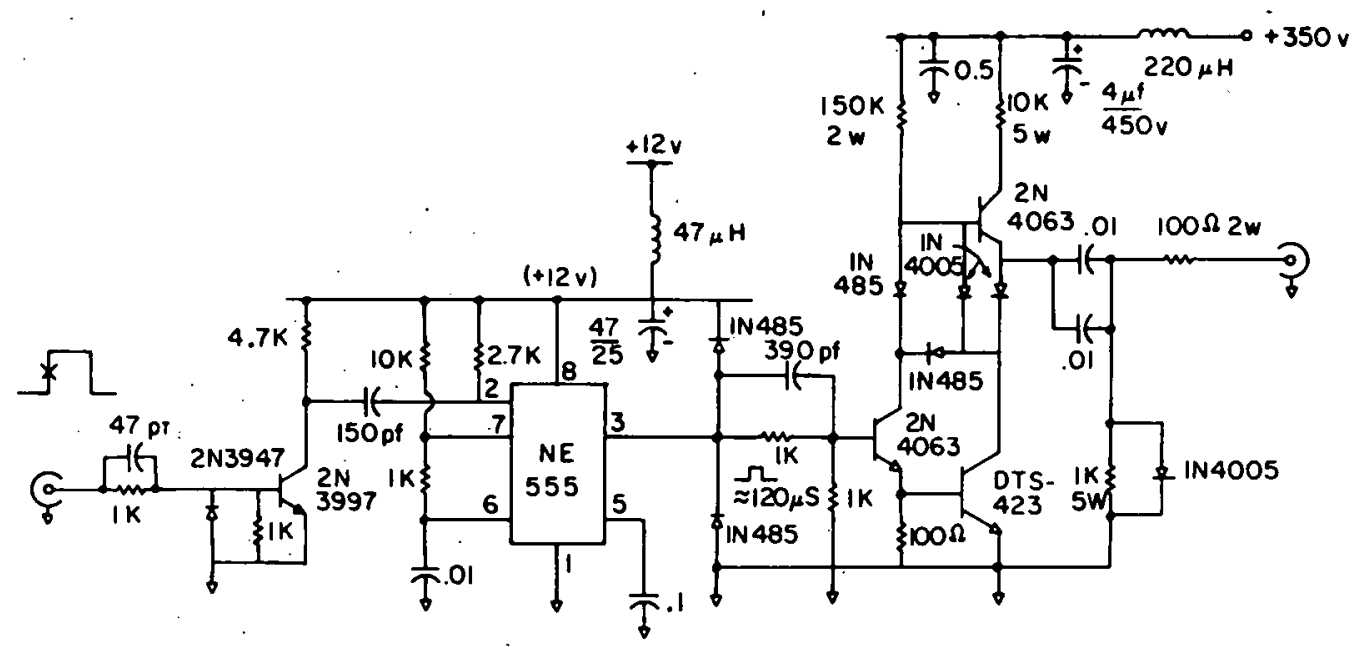

Fig. A3. Field-coil Pulser. Neg. No. MSD-64455.

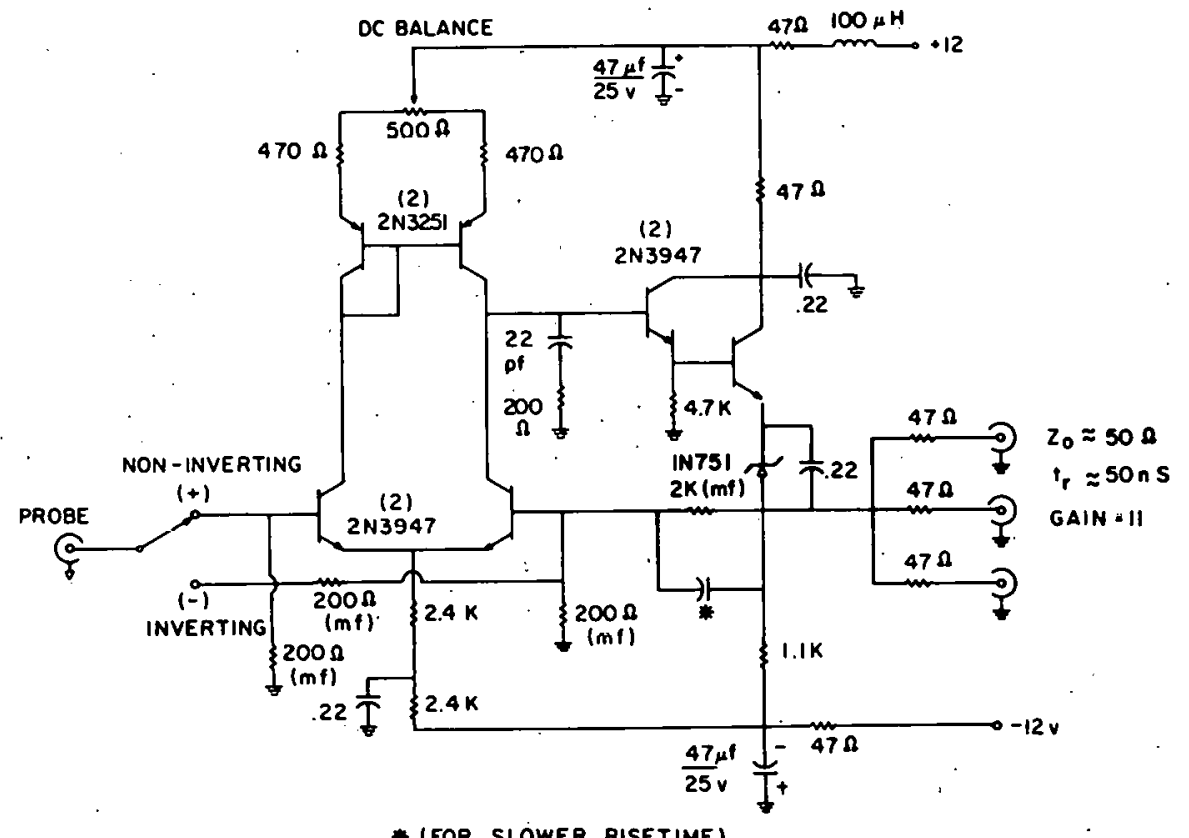

Fig. A4. Pickup Preamplifier for Defect Section. Neg. No. MSD-64457.

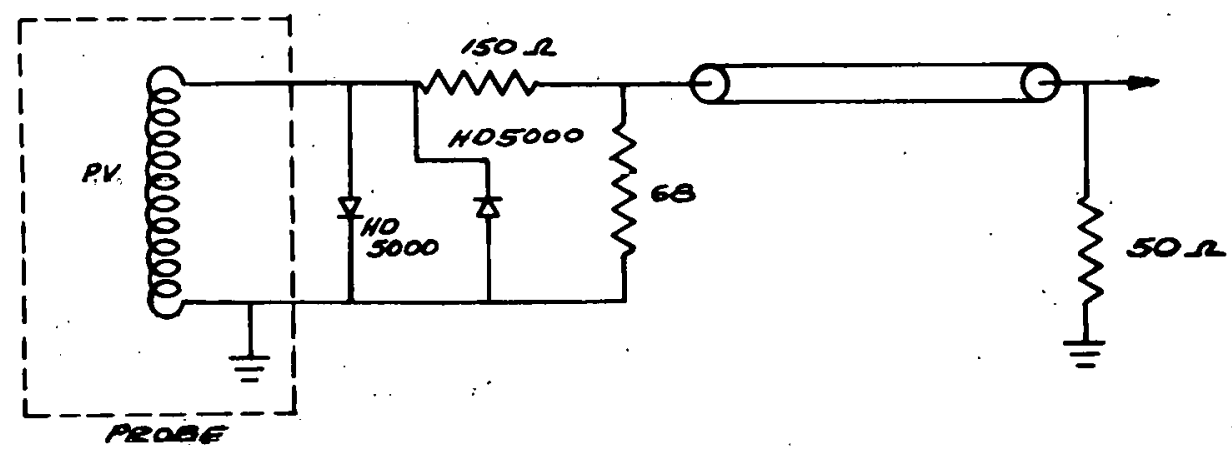

Fig. A5. Wall-thickness Section Pulse-forming Network. Neg. No. MSD-64458. 


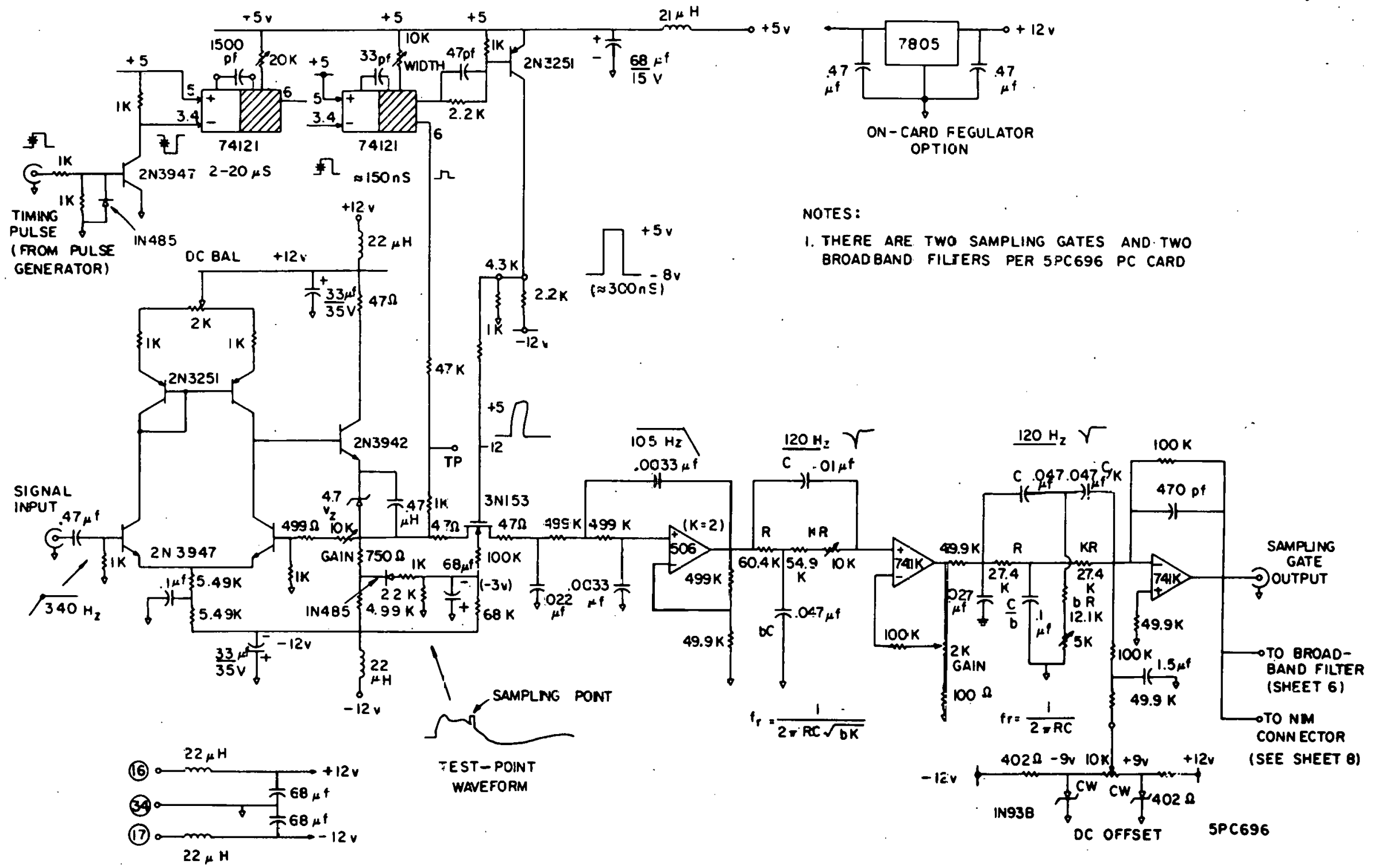

Fig. A6. Wall-thickness Secticn Sampling Gate (5A in Fig. A1). Neg. No. MSD-64452. 


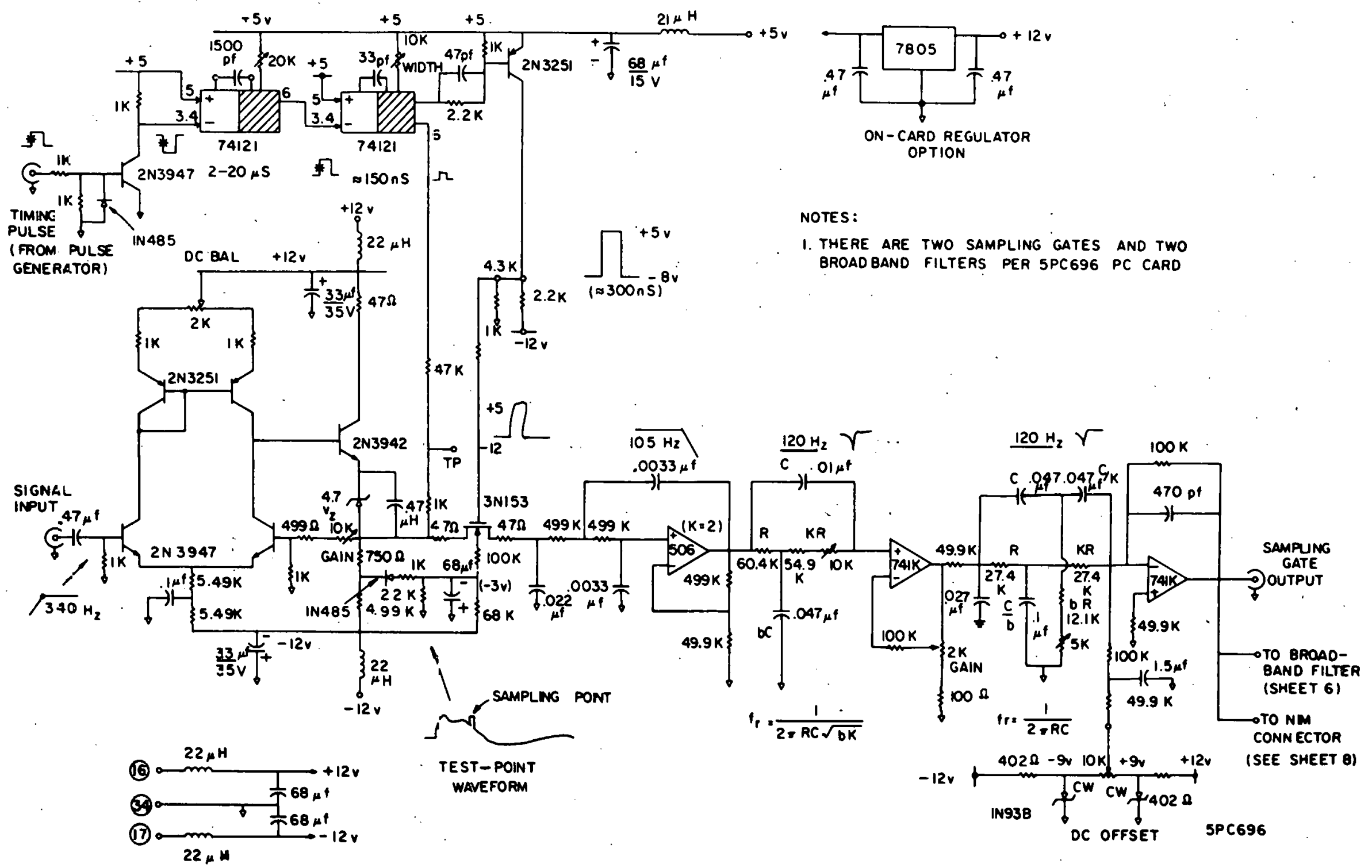

Fig. A7. Defect Section Sampling Gate (5B in Fig. A1). Neg. No. MSD-64451. 


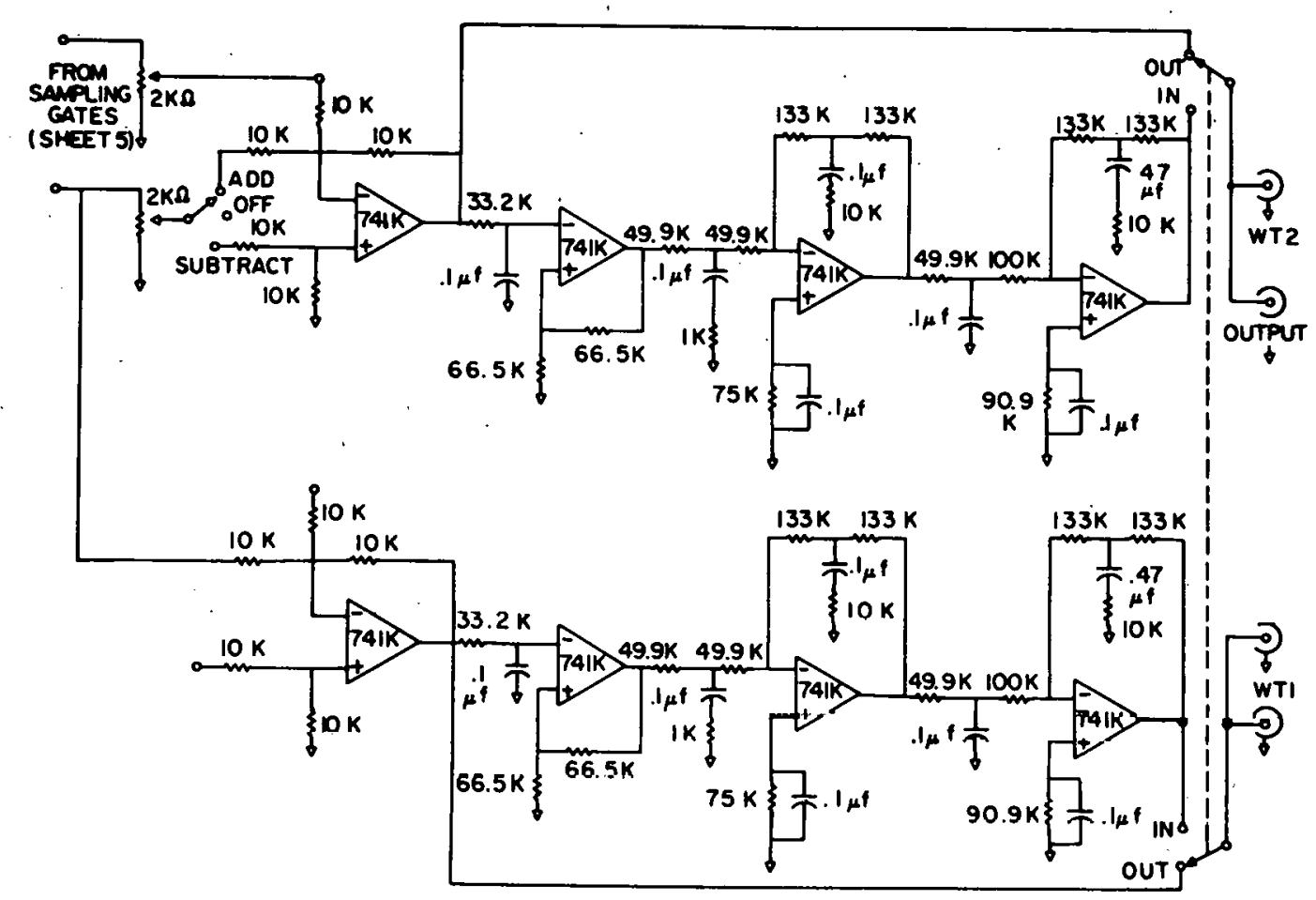

Fig. A8. Wall-thickness Section Broadband Filter with AddSubtract Circuit (6A in Fig. A1). Neg. No. MSD-64459.

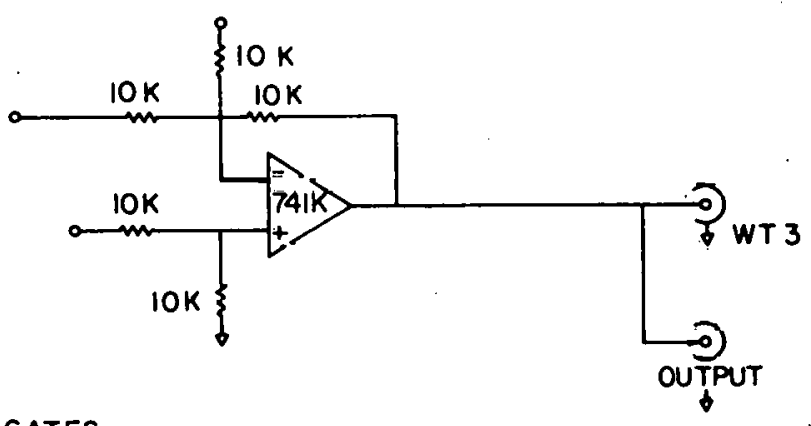

FROM SAMPLING GATES

(SHEET 5)

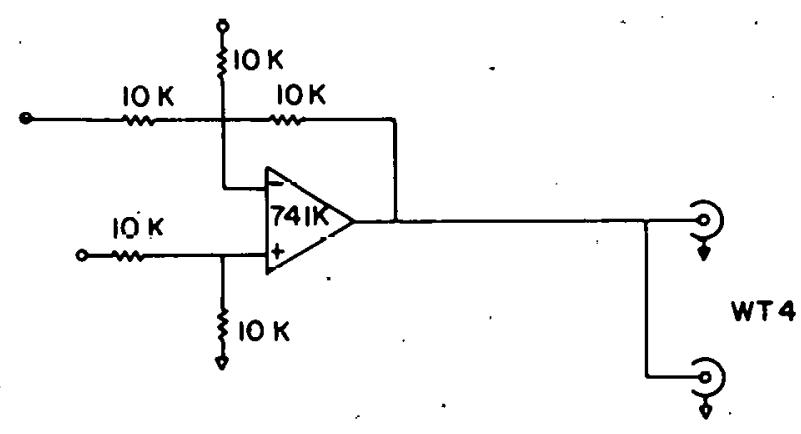

Fig. A9. Wall-thickness Section Broadband Filter Inverter Buffers (6B in Fig. A1). Neg. No. MSD-64462. 


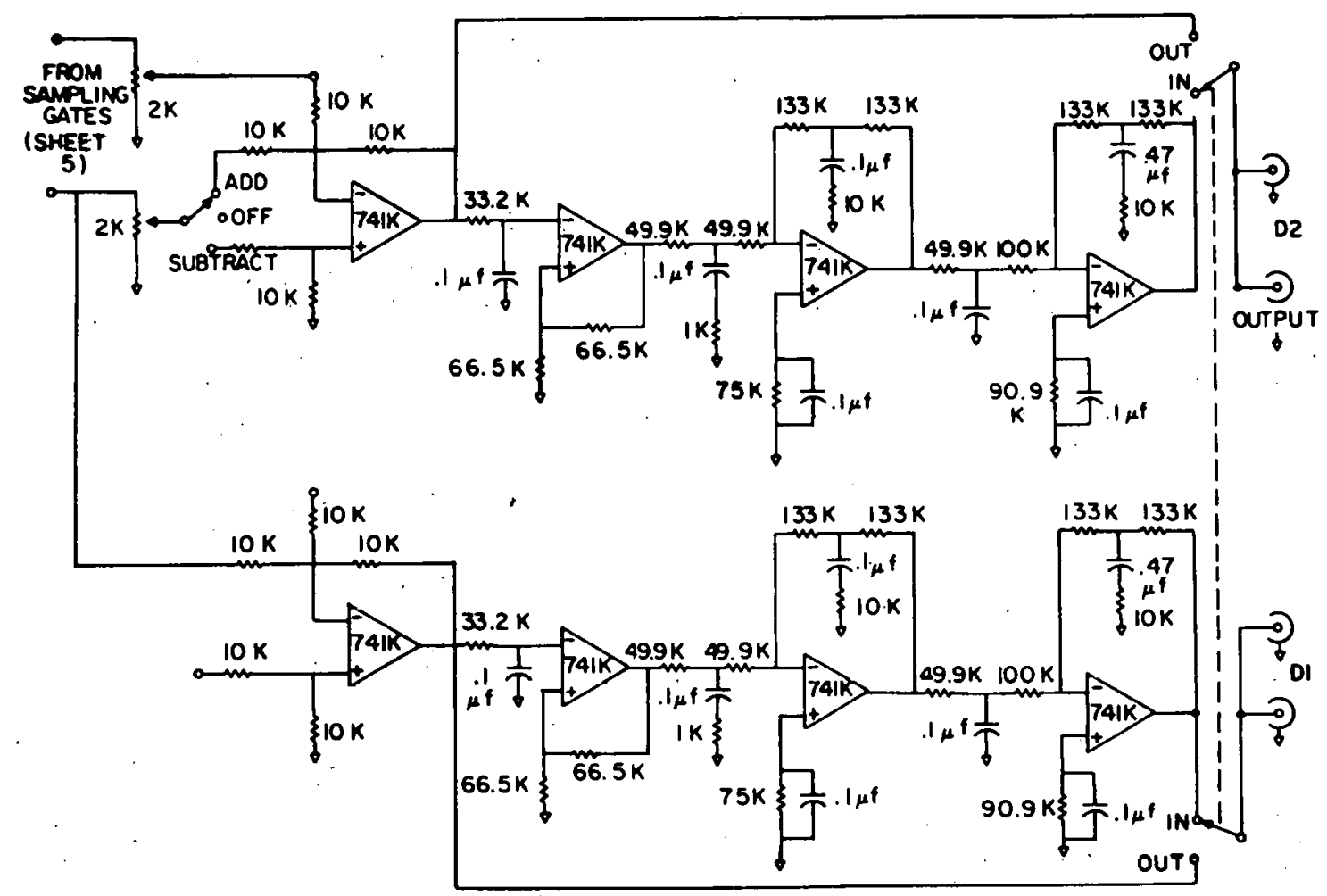

Fig. A10. Defect Section Broadband Filter with Add-Subtract Circuit. (6C in Fig. A1). Neg. No. MSD-64456.

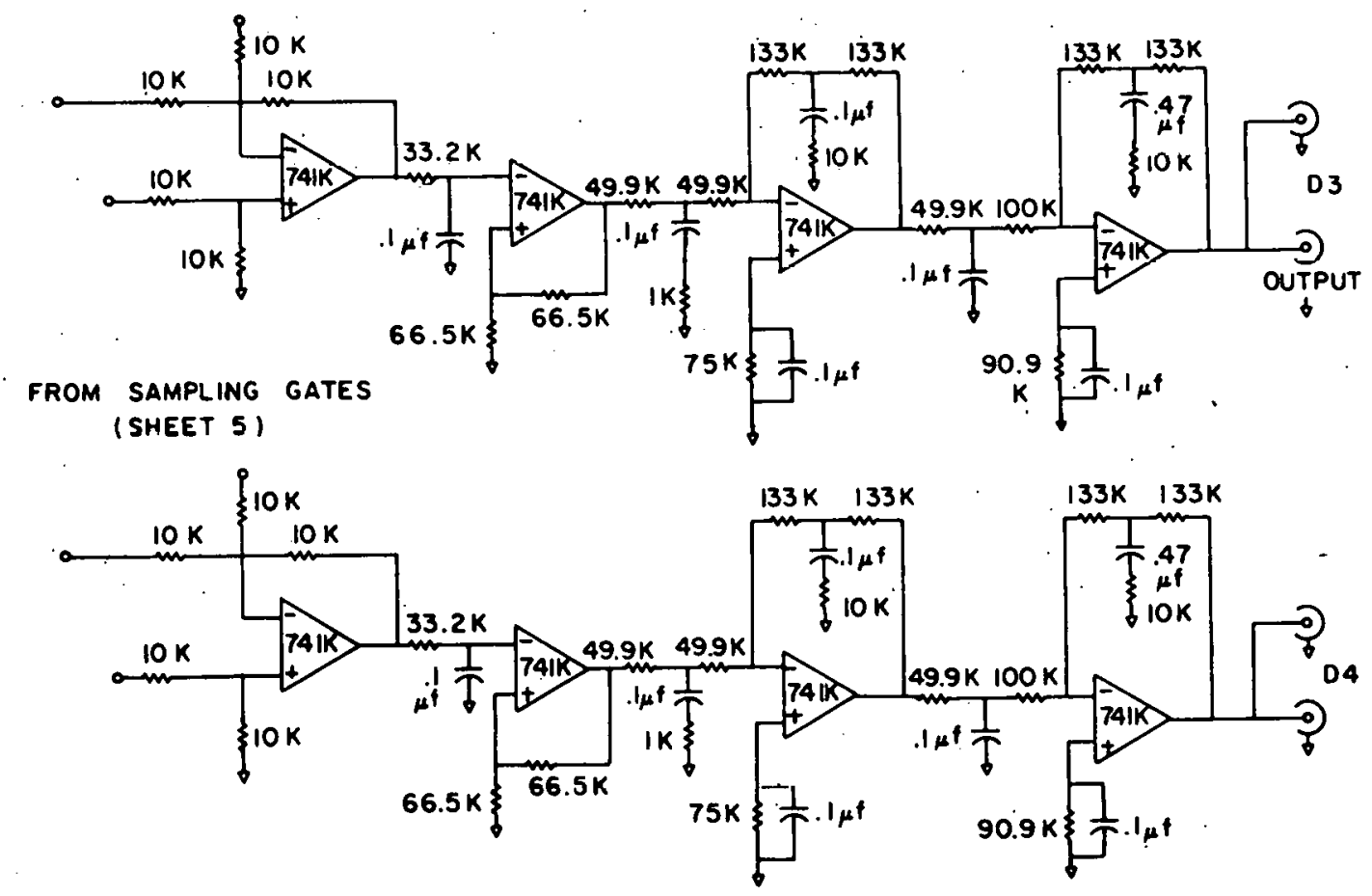

Fig. A11. Defect Section Broadband Filter (6D in Fig. A1). Neg. No. MSD-64454. 


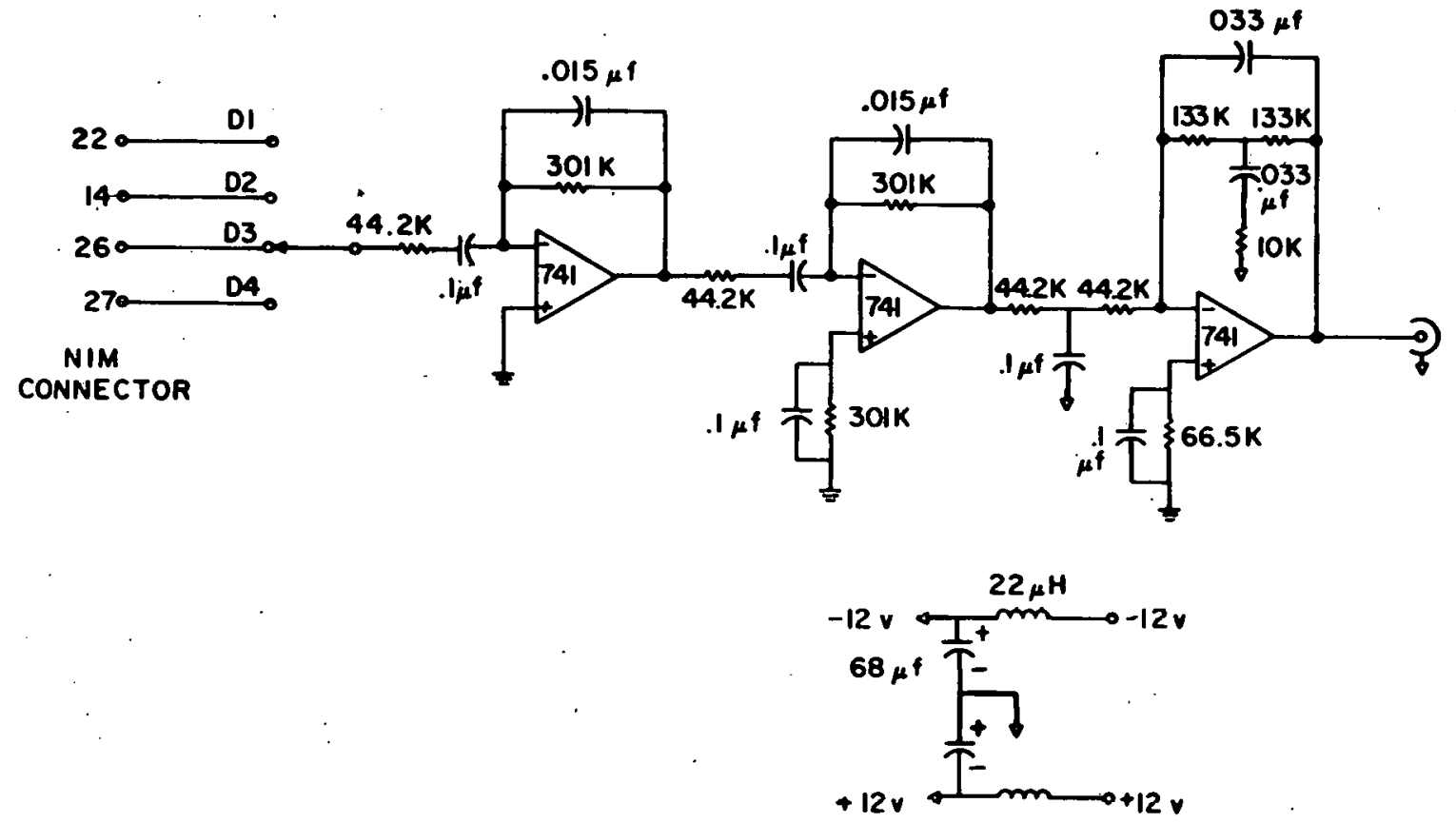

Fig. A12. Matched Filter. Neg. No. MSD-64460.

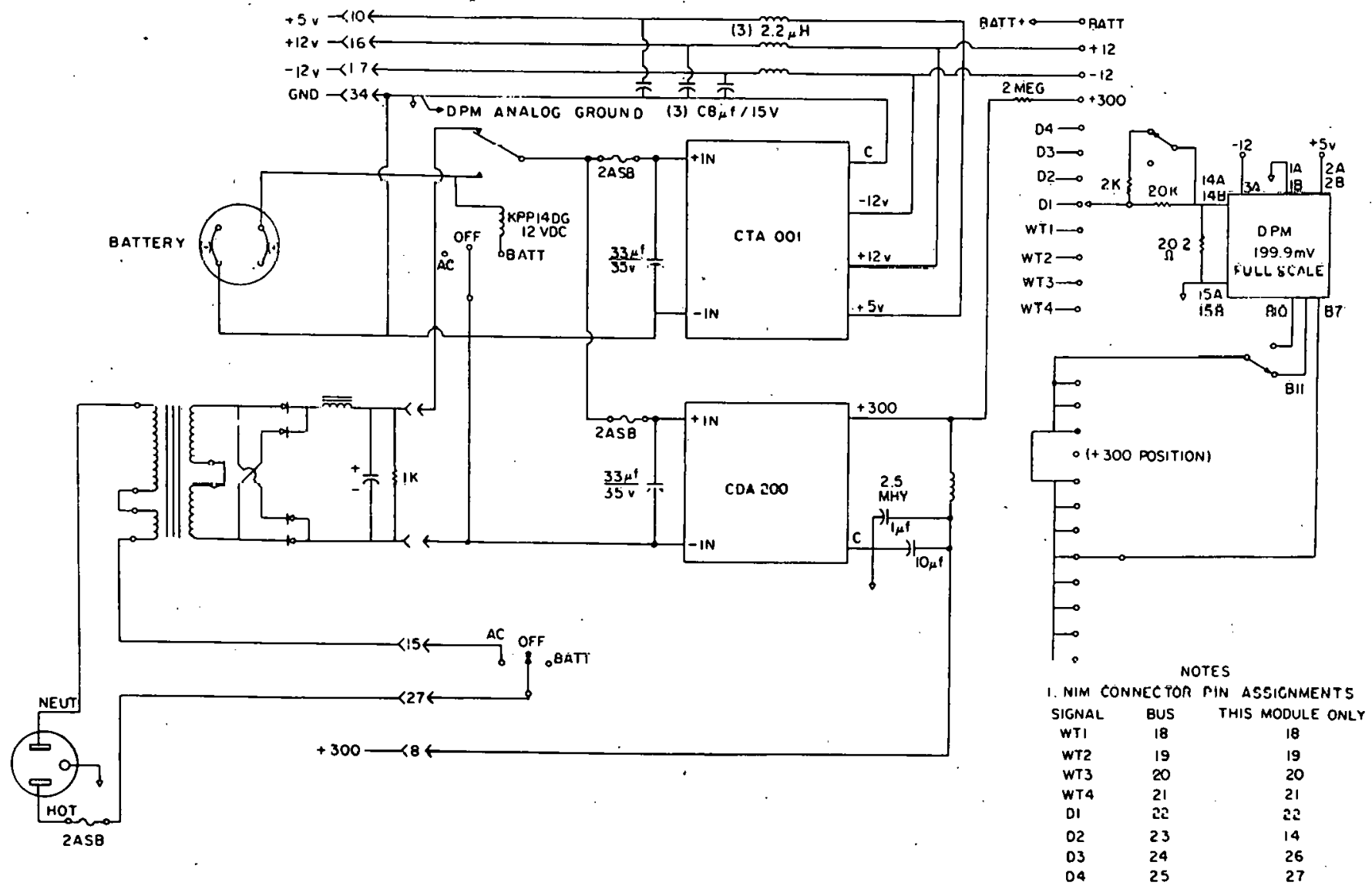

Fig. A13. Power Supply. Neg. No. MSD-64450. 


\section{REFERENCES}

1. C. J. Renken, "The Application of Pulsed-Electromagnetic.Field Methods to Liquid-Metal Fast Reactor Nondestructive Test Problems," in $12^{e}$ Colloque de Metallurgie on Non Destructive Testing and Control in the Field of Nuclear Metaliurgy and Technology, Presses Universitaires de France, Paris, France (1969), p. 119.

2. D. L. Waidelich and S. C. Huang, "The Use of Crossing Points in Pulsed Eddy Current Testing," Mater. Eval. 30(1), 20 (1972).

3. C. J. Renken, "The Role of High Resolution Fields and Filtering in Eddy Current Testing," Mater. Eval. 26(9), 191 (1968):

4. C. W. Cox and C. J. Renken, "The Application of Signal-Processing Techniques to Signals from Electromagnetic Test Systems," Mater. Eval. 28(8), 173 (1970).

5. C. J. Renken and Allen Sather, Pulsed Eddy-current Test System for Hot Cell Use: Manual of Operation, Argonne National Laboratory, ANL-7973 (November 1972). 
Distribution of ANL-77-53

Internal:
J. A. Kyger
J. F. Schumar
D. Stahl
R. Avery
M. F. Adams (2)
D. J. Lam
L. Burris
M. C. Billone
D. W. Cissel
R. B. Poeppel
N. L. Peterson
S. A. Davis
T. F. Kassner
B. S. Brown
B. R. T. Frost
L. A. Neimark
K. L. Merkle
D. C. Rardin
S. Greenberg
R. J. Teunis
H. R. Thresh
C. E. Till
A. G. Hins
R. S. Zeno
D. R. Diercks
H. O. Mons on
K. J. Reimann
R. W. Weeks
F. L. Yaggee
F. Y. Fradin
A. Purohit
F. A. Nvichols
W. A. Ellingson
M. B. Brodsky
H. Wiedersich
U. F. Kocks
R. W. Siegel
M. H. Mueller
L. T. Lloyd
A. Sather (10)
A. B. Krisciunas
ANL Contract File
ANL Libraries (5)
TIS Files (6)

\section{External:}

DOE-TIC, for distribution per UC-79b (284)

Manager, Chicago Operations Office

Chief, Chicago Patent Group

Director, Reactor Programs Div., $\mathrm{CH}$

Director, CH-INEL

Director, DOE-RRT (2)

President, Argonne Universities Association

Materials Science Division Review Committee:

G. S. Ansell, Rensselaer Polytechnic Inst.

R. W. Balluffi, Cornell U.

S. L. Cooper, U. Wisconsin

S. Doniach, Stanford U.

H. L. Falkenberry, Tennessee Valley Authority

C. Laird, U. Tennsylvania

D. Lazarus, U. Illinois

M. T. Simnad, General Atomic

A. R. C. Westwood, Martin Marietta Labs. 